\section{Comparing Three Solutions for Extracting Western Flower Thrips from Coleus Shoots}

\author{
Daniel F. Warnock ${ }^{1}$ and Rebecca Loughner ${ }^{2}$ \\ University of Illinois, Department of Natural Resources and Environmental \\ Sciences, 1201 South Dorner Drive, Urbana, IL 61801 \\ Additional index words. floriculture, production, Frankliniella occidentalis, coleus
}

\begin{abstract}
Western flower thrips [Frankliniella occidentalis (Pergande)] are small-bodied insects that prefer tight spaces such as flower buds and young leaves. Western flower thrips (WFT) pose sampling problems when compared with larger insects commonly found in plant canopies. Techniques to wash insects from plant canopies exist; however, plant type, plant age, and spatial distribution of insects within the canopy impact the efficacy of sampling. An experiment was designed to determine if $75 \%$ ethyl alcohol (EtOH), $0.1 \%$ detergent solution, or deionized water effectively wash WFT from the foliage of six coleus [Solenostemon scutellarioides $(\mathrm{L}$.$) Codd] genotypes inoculated with 32$ adults and larvae. The number of WFT recovered after filtration through three mesh sizes varied between blocks and extraction solutions. The mean number of thrips recovered from coleus shoots with $75 \%$ EtOH solution, $0.1 \%$ detergent solution, or deionized water was $6.7,8.4$, or 0.8 , respectively. The number of thrips recovered did not vary by coleus genotype, indicating the extraction solutions were equally effective on smooth leaf or curly leaf type plants. The 75\% EtOH extraction solution is recommended for subsequent experiments.
\end{abstract}

Consumers purchasing floriculture crops typically base their decision on aesthetics. Producers therefore must grow a crop with few or no blemishes or pests (Sunderland et al., 1992). Western flower thrips (WFT) is a serious pest of the floricultural industry (Robb et al., 1995) attacking a multitude of crops. Thrips seek tight crevices, lay eggs inside plant tissues, and have a high level of pesticide resistance in some populations (Childers and Achor, 1995; Immaraju et al., 1992; Robb et al., 1995). Feeding damage of WFT is expressed as silver mottling or blotching, streaking, and distortion of the leaves and/or petals, which reduces the aesthetic quality and marketability of floricultural crops (Parrella and Jones, 1987). WFT also vector tomato spotted wilt virus and impatiens necrotic spot virus, both of which can devastate ornamental crops. Initially confined to the western United States and Canada, international transport of infested floral products has resulted in the presence of WFT and associated plant viruses in commercial greenhouses throughout the world (Parrella, 1995; Schreiter et al., 1995).

Integrated pest management (IPM) programs seek to balance proactive cultural controls with minimal pesticide inputs during crop production. Mound and Teulon (1995) suggest that host plant resistance, a component of IPM programs, might be a good control strategy for WFT. Host plant resistance may

Received for publication 27 Nov. 2001. Accepted for publication 27 Feb. 2002. This research was supported in part by USDA CRIS Hatch Project ILLU-65-0308.

${ }^{1}$ Assistant Professor. To whom reprint requests should be addressed. Phone: (217) 244-9380;

e-mail: dwarnock@uiuc.edu

${ }^{2}$ Graduate Student. depress WFT reproduction rates thereby increasing the efficacy of other IPM management components. Research in the area of host plant resistance indicates that some chrysanthemum (Dendranthema $\times$ grandiflorum Kitam), gladiolus (Gladiolus grandiflorus Linn.), and impatiens (Impatiens wallerana Hook. f.) cultivars may have improved levels of resistance to thrips (Herrin and Warnock, 2002; van Dijken et al., 1995; Zeier and Wright, 1995). Currently, resistant cultivars are not routinely used to manage WFT in commercial production facilities.

The continued search for host plant resistance to thrips will provide growers with an economically feasible component for use in IPM programs to limit thrips damage. To identify cultivars with improved levels of insect resistance, several components of a host plant resistance development model are needed: a method for mass rearing the insect pest, reliable inoculation and evaluation methods, and availability of germplasm with genetic variation in resistance levels. Rearing (Steiner and Goodwin, 1998), inoculation (Cloyd et al., 2001), and visual evaluation (Herrin and Warnock, 2002) protocols for WFT feeding assays exist. These protocols, however, cannot determine if antibiosis mechanisms impact plant resistance to WFT.

Determining the number of insects on plants is necessary to identify if antibiosis mechanisms contribute to improved plant resistance to insect damage. Cho et al. (1995) immersed tomato (Lycopersicon esculentum Mill.) flowers in $70 \% \mathrm{EtOH}$, hand agitated, and counted the number of thrips in each sample. They determined that 10 flowers for each sampling accurately measured the population level of thrips in tomato. Shipp and Zariffa (1991) used detergent to wash thrips from whole pepper plants (Capsicum annuum L.) before counting the insects. Irwin et al. (1979) used both alcohol and detergent solutions combined with filtration through fine mesh to extract thrips from soybean [Glycine $\max (\mathrm{L}$.) Merrill] plants. These washing methods generally are used to remove insects from many plant species; however, Lewis (1997) stated that researchers sampling different insect species and crops needed to use a separate approach for each species or crop to meet the objectives of the researcher. For most host plant resistance breeding programs, researchers are interested in obtaining relative levels of insects on specific plant genotypes as opposed to absolute numbers. Washing insects from plant tissues is one method of obtaining a representative sample of insect population levels (Lewis, 1997). To adapt existing protocols for extracting WFT, an experiment was designed to examine the extraction efficacy of three solutions in removing thrips from coleus shoots.

\section{Materials and Methods}

Six diverse coleus genotypes, 'Alabama Sunset', 'Ducksfoot Midnight', 'Golden Bedder', 'Paisley Shaw', 'Red Velvet', and 'Saturn', were grown in a glass-covered greenhouse in Urbana, Ill., using standard production parameters (Ball, 1998) except that no insecticides were applied. The coleus genotypes varied in leaf color (light green to deep red), leaf variegation (solid to highly variegated), leaf shape (oblong entire margins to finely dissected), and leaf texture (smooth to curly). Nine terminal cuttings were obtained from each of six coleus genotypes on 6 June 2000, dipped in $0.3 \%(\mathrm{w} / \mathrm{w})$ indolebutyric acid (IBA) rooting powder (Hormex \#3; Brooker Chemical, North Hollywood, Calif.), inserted into Jiffy-7 peat pellets (Jiffy Products, Shippagan, Canada), and placed under intermittent mist in a glass greenhouse at 21 to $24^{\circ} \mathrm{C}$ and ambient irradiance. Upon root emergence, each terminal cutting was transplanted into a $12.7-\mathrm{cm}(1.24 \mathrm{~L})$ azalea pot filled with a soilless media (Strong-Lite Universal Mix, Seneca, Ill.) on 20 June 2000. Transplanted cuttings were placed in a randomized block design with three blocks.

For each coleus genotype, blocks consisted of three single-plant replications assigned one of three extraction solutions: $75 \%$ EtOH, $0.1 \%$ (v/v) detergent (Triton X; Sigma, St. Louis) in deionized water, or deionized water (control). The 54 plants were individually covered with a vented isolation cage $[62 \mathrm{~cm}$ high and $12 \mathrm{~cm}$ diameter with $135-\mu \mathrm{m}$ thrips screening (Greenthumb Group, Downers Grove, Ill.) covering vents] to prevent WFT infestations prior to inoculation. On 11 July 2000, each plant was inoculated with 32 laboratory-reared WFT. The WFT used for inoculations consisted of $\approx 67 \%$ adults and $33 \%$ instars. Thrips were allowed to disperse on the plants for $48 \mathrm{~h}$ after which plants were transferred to a laboratory for insect extraction and data collection.

Each plant was sheared at soil level, cut into $5-\mathrm{cm}$ sections as the plant shoots were 
being removed from the isolation cage, and immediately immersed in $250 \mathrm{~mL}$ of an extraction solution. WFT remaining in the isolation cage were removed and immersed in the solution. Tissues immersed in the extraction solutions were then placed on an Innova 2100 platform shaker (New Brunswick Scientific, Edison, N.J.) at $125 \mathrm{rpm}$ for $5 \mathrm{~min}$. After agitation, WFT were separated from plant tissues by sequentially filtering through three mesh screens with pore sizes of $2 \mathrm{~mm}, 707 \mu \mathrm{m}$, and $135 \mu \mathrm{m}$. Thrips and plant residue collected on the $135-\mu \mathrm{m}$ screens were sprayed with $95 \% \mathrm{EtOH}$ to immobilize any living thrips. Thrips were then counted under magnification with a grid and stereomicroscope (Lecia GZ4, Buffalo, N.Y.). Data were analyzed using the general linear models procedure of SAS software (SAS Institute, Cary, N.C.). Means were separated using Fisher's protected least significant difference test at $P$ $\leq 0.05$.

\section{Results and Discussion}

The number of WFT recovered varied significantly between block and extraction solution (Table 1). A significant two-way interaction existed between block and extraction solution (Table 1). Coleus genotype and associated interactions did not impact the number of WFT recovered (Table 1).

The block $\times$ extraction solution interaction for the number of WFT recovered is shown in Fig. 1. The $75 \% \mathrm{EtOH}$ and $0.1 \%$ detergent solutions extracted a higher number of WFT than the deionized water solution. The EtOH and detergent solutions resulted in a mean of 6.7 and 8.4 WFT representing a recovery percentage of 20.9 and 27.8, respectively. The deionized water solution had a recovery percentage of 2.5. WFT extracted with the detergent solution or deionized water appeared unharmed by the extraction process and required a misting with $95 \%$ EtOH before accurate counts could be conducted. Thrips extracted with $75 \%$ EtOH were intact but rarely alive after the extraction process. Thus, the 95\% EtOH misting could be eliminated when

Table 1. Analysis of variance for the number of western flower thrips (WFT) recovered from six coleus genotypes using one of three extraction solutions: $75 \% \mathrm{EtOH}, 0.1 \%$ (v/v) detergent in deionized water, or deionized water. Nine plants of each coleus genotype inoculated with 32 thrips were coarsely chopped, immersed in a solution, shaken, and sequentially filtered through 2-, 707-, and 135-mm mesh screens. Recovered thrips were then counted using a stereomicroscope.

\begin{tabular}{|c|c|c|c|}
\hline \multirow[b]{2}{*}{ Source } & \multicolumn{3}{|c|}{ No. of thrips recovered } \\
\hline & $\mathrm{df}$ & Mean square & $P$ \\
\hline Block (B) & 2 & 32.02 & * \\
\hline Solution (S) & 2 & 285.35 & $* * *$ \\
\hline Genotype (G) & 5 & 2.64 & NS \\
\hline $\mathrm{B} \times \mathrm{S}$ & 4 & 37.35 & ** \\
\hline$B \times G$ & 10 & 10.24 & NS \\
\hline $\mathrm{S} \times \mathrm{G}$ & 10 & 6.31 & NS \\
\hline
\end{tabular}

0.01 , or 0.001 , respectively. using the $75 \%$ EtOH solution in future experiments. With the exception of block 3 , the number of WFT recovered in the $75 \% \mathrm{EtOH}$ or the $0.1 \%$ detergent solutions was similar (Fig. 1). A mean of 13.0 WFT was recovered in block 3 using the $0.1 \%$ detergent solution compared to means of 6.7 and 5.7 for blocks 1 and 2 , respectively. The cause of this increased recovery rate is unknown.

The number of WFT recovered with these extraction methods was lower than expected. Several factors may be associated with the low number of recovered WFT. Spatial distribution of WFT within the isolation cages may have impacted the efficacy of sampling. Extraction occurred $48 \mathrm{~h}$ after inoculation with various aged WFT. Given the greenhouse teminstar WFT could have pupated while adult WFT could have completed their lifecycle. In both instances, WFT would have escaped recovery with the current extraction methods as pupae are often in the soil and expired WFT would have fallen from the plant canopy.

No extraction process will result in recovery rates of $100 \%$ every time the process is used. The three extraction methods used in this experiment are no exception. WFT may escape during plant dissection, tissue immersion, or the filtering process. The current agitation method was gentle due to solution volume and limitations of laboratory equipment. Increasing the agitation rate or time may increase WFT recovery rate. Though thoroughly probed, some recovered WFT possibly were hidden in plant debris on the 135 -mm screen and remained undetected.

The number of recovered WFT usually was consistent within extraction solution (Fig. peratures during the experiment, many of the

1) but varied between the three solutions (Table 1). Researchers can obtain relative levels of insects but not absolute numbers using any of the three solutions. Similar numbers of WFT were recovered from each coleus genotype examined. Thus, these extraction methods are general and applicable across plant types making them valuable to most host plant resistance breeding programs.

\section{Conclusions}

WFT can be extracted from coleus plant tissues using a $75 \% \mathrm{EtOH}$ or $0.1 \%$ detergent solution and gentle agitation on a shaker platform. Recovery of thrips for these solutions, although $<30 \%$, surpassed the number of thrips recovered with deionized water. The $75 \%$ EtOH extraction solution effectively immobilized WFT, eliminating the need for a postextraction spray of $95 \% \mathrm{EtOH}$. Recovery of WFT from the various coleus genotypes was similar, suggesting that the extraction solutions used in this experiment are general and applicable across plant types. Future experiments should employ a $75 \%$ EtOH extraction solution and at least a 5-min agitation at $125 \mathrm{rpm}$ to remove WFT from plants.

\section{Literature Cited}

Ball, V. 1998. Coleus, p. 434-435. In: V. Ball (ed.). Ball redbook 16th ed. Ball Publishing, Batavia, IIl.

Childers, C.C. and D.S. Achor. 1995. Thrips feeding and oviposition injuries to economic plants, subsequent damage and host response to infection, p. 31-51. In: B.L. Parker, M. Skinner, and T. Lewis (eds.). Thrips biology and management. Plenum Press, New York.

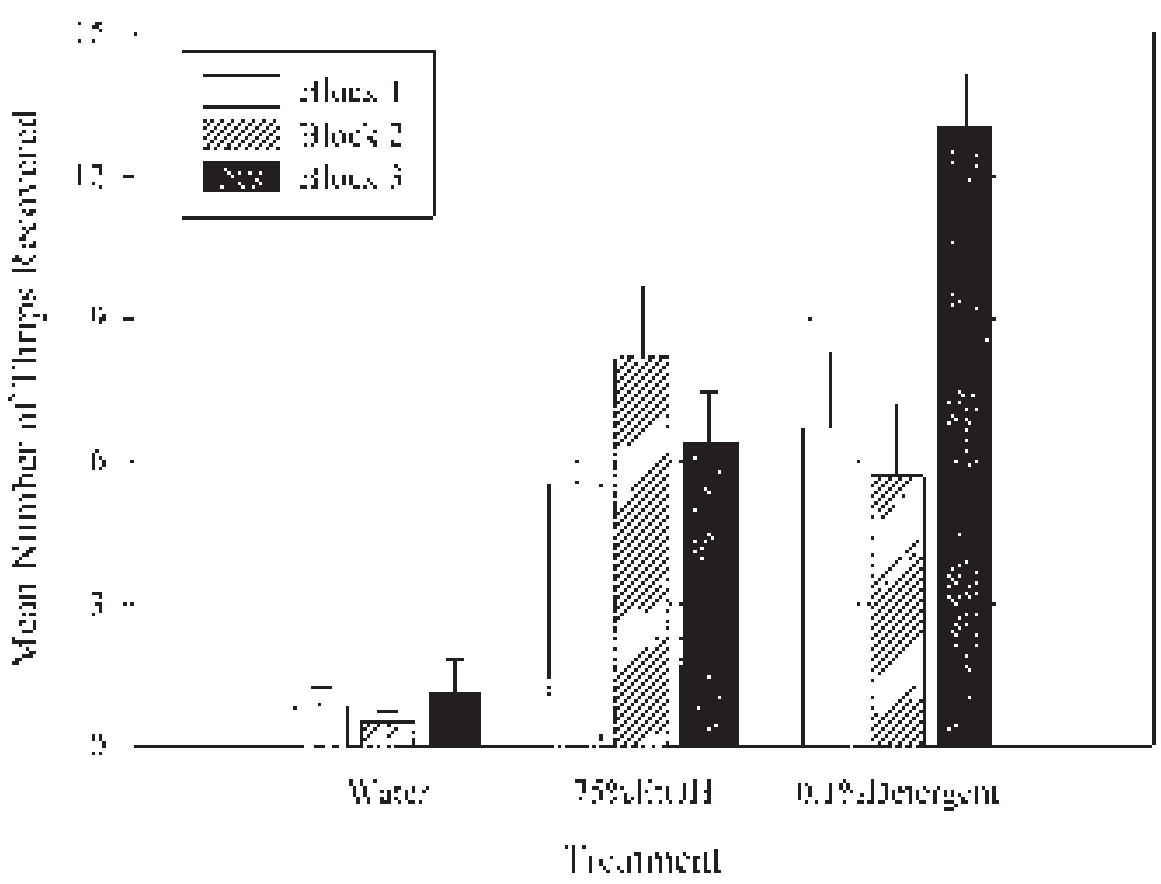

Fig. 1. Mean number of western flower thrips (WFT) in each of three blocks that were recovered from six coleus genotypes using one of three extraction solutions. Coleus plants inoculated with 32 thrips were coarsely chopped, immersed in a solution, shaken, and sequentially filtered through 2-, 707-, and 135$\mathrm{mm}$ mesh screens. Recovered WFT were then counted using a stereomicroscope. Vertical bars represent the mean of 6 observations \pm standard error. 
Cho, K., C.S. Eckel, J.F. Walgenbach, and G.G. Kennedy. 1995. Spatial distribution and sampling procedures for Frankliniella spp. (Thysanoptera: Thripidae) in staked tomato. J. Econ. Entomol. 88:1658-1665.

Cloyd, R., D.F. Warnock, and K. Holmes. 2001. Technique for collecting thrips for use in insecticide efficacy trials. HortScience 36:925-926.

Herrin, B. and D. Warnock. 2002. Resistance of impatiens germplasm to western flower thrips feeding damage. HortScience 37:802-804.

Immaraju, J.A., T.D. Paine, J.A. Bethke, K.L. Robb, and J.P. Newman. 1992. Western flower thrips (Thysanoptera: Thripidae) resistance to insecticides in coastal California greenhouses. J. Econ. Entomol. 85:9-14.

Irwin, M.E., K.V. Yeargan, and N.L. Marston. 1979. Spatial and seasonal patterns of phytophagous thrips in soybean fields with comments on sampling techniques. Environ. Entomol. 8:131-140.

Lewis, T. 1997. Field and laboratory techniques, p. 435-475. In: T. Lewis (ed.). Thrips as crop pests. CAB Intl., Wallingford, Oxon, U.K.
Mound,L.A. and D.A.J.Teulon. 1995. Thysanoptera as phytophagous opportunists, p. 3-21. In: B.L. Parker, M. Skinner, and T. Lewis (eds.). Thrips biology and management. Plenum Press, New York.

Parrella, M.P. 1995. IPM: Approaches and prospects, p. 357-363. In: B.L. Parker, M. Skinner, and T. Lewis (eds.). Thrips biology and management. Plenum Press, New York.

Parrella, M.P. and V.P. Jones. 1987. Development of integrated pest management strategies in floricultural crops. Bul. Entomol. Soc. Amer. 33:28-34.

Robb, K.L., J. Newman, J.K. Virzi, and M.P. Parrella. 1995. Insecticide resistance in western flower thrips, p. 341-346. In: B.L. Parker, M. Skinner, and T. Lewis (eds.). Thrips biology and management. Plenum Press, New York.

Schreiter, G., T.M. Butt, A. Beckett, and G. Moritz. 1995. Electron microscope studies of infection by Verticillium lecanii (Zimm.) Viégas of western flower thrips, p. 297-304. In: B.L. Parker, M. Skinner, and T. Lewis (eds.). Thrips biology and management. Plenum Press, New York.
Shipp, J.L. and N. Zariffa. 1991. Spatial patterns of and sampling methods for western flower thrips (Thysanoptera: Thripidae) on greenhouse sweet pepper. Can. Entomol. 123:989-1000.

Steiner, M.Y. and S. Goodwin. 1998. Methods for collecting and rearing thrips (Thysanoptera) and their natural enemies. Austral. J. Entomol. 37:101-106.

Sunderland, K.D., R.J. Chambers, N.L. Helyer, and P.I. Sopp. 1992. Integrated pest management of greenhouse crops in northern Europe, p. 1-66. In: J. Janick (ed.). Horticultural reviews. Vol. 13. Wiley, New York.

van Dijken, F.R., C. Mollema, and J. de Jong. 1995. Host plant resistance to western flower thrips in chrysanthemum, p. 407-410. In: B.L. Parker, M. Skinner, and T. Lewis (eds.). Thrips biology and management. Plenum Press, New York.

Zeier, P. and M.G. Wright. 1995. Thrips resistance in Gladiolus spp.: Potential for IPM and breeding, p. 411-416. In: B.L. Parker, M. Skinner, and T. Lewis (eds.). Thrips biology and management. Plenum Press, New York. 